\title{
Sucção não-nutritiva em neonatos e lactentes impossibilitados de amamentação
}

\author{
Bárbara Alves Brasil Anschau*, Maria Filomena Vancelotte Pereira de Almeida**
}

\begin{abstract}
*Acadêmica do Curso de Enfermagem da Escola de Enfermagem Alfredo Pinto da Universidade Federal do Estado do Rio de Janeiro, ${ }^{* *}$ Orientadora, Professora Adjunta do Departamento Materno-Infantil da Escola de Enfermagem Alfredo Pinto da Universidade Federal do Estado do Rio de Janeiro
\end{abstract}

\section{Resumo}

Objetivos: Descrever a atuação da enfermagem em relação à prática terapêutica de estímulo à sucção não-nutritiva em neonatos e lactentes impossibilitados de amamentaçáo, bem como identificar, em publicaçôes de enfermagem, os resultados esperados ou obtidos a partir desta atividade terapêutica. Metodologia: Estudo bibliográfico com abordagem descritiva, tendo como fontes para o levantamento da produção científica, a Biblioteca Virtual em Saúde (BVS) e Ovid Technologies. Resultados: Como conseqüências da estimulação por sucção não-nutritiva em neonatos, destacam-se: maior consumo e ingestão, em menor tempo, da alimentação oral prescrita; maior ganho de peso; alta hospitalar precoce; melhora no estado de consciência durante a alimentação; indução de sono, redução do choro e aumento do limiar álgico, em processos dolorosos. Conclusão: Não foram encontrados artigos de enfermagem que abordem a atuação desta na prática terapêutica de estímulo à sucção nãonutritiva, em neonatos e em lactentes impossibilitados de amamentaçáo, assim como, artigos que mencionem seus benefícios orofaciais. Os resultados obtidos foram baseados na reduzida bibliografia relacionada à temática.

Palavras-chave: estimulação, sucção não-nutritiva, neonatos, lactentes.

\section{Abstract \\ Non-nutritive sucking in neonates and infants unable to be breastfeed}

Objectives: To describe nursing performance related to stimulation of non-nutritive sucking in neonates and infants unable to be breastfeed, and to identify, in nursing reviews, results related to this therapy. Methodology: It is a literature review, with descriptive approach, using as databases Virtual Health Library (VHL) and Ovid Technologies. Results: As consequences of the non-nutritive sucking in neonates, are mentioned: high consumption as well as ingestion of the prescribed diet in a small period of time; high weight gain; earlier hospital discharge; improving consciousness state during feeding; sleep induction, crying time reduction and increase in pain threshold. Conclusion: We did not find nursing articles referring to non-nutritive sucking stimulation therapy in neonates and infants which are unable to be breastfeed, and also, the orofacial benefits of this practice. The results were based on the small literature related to the theme.

Key-words: stimulation, non-nutritive sucking, neonates, infants. 


\section{Resumen}

\section{Succión no nutritiva en neonatos y lactantes imposibilitados de amamantamiento}

Objetivos: Describir la actuación de enfermería con relación a la estimulación terapéutica de succión no nutritiva en neonatos y lactantes imposibilitados de ser amamantados, así como identificar, en publicaciones de enfermería, los resultados obtenidos referente a esta actividad terapéutica. Metodología: Estudio bibliográfico descriptivo que utilizó las bases de datos de la Biblioteca Virtual en Salud (BVS) y el Ovid Technologies para analizar la producción científica referente al tema en cuestión. Resultados: La estimulación por succión no nutritiva en neonatos trae como consecuencias: un mayor consumo e ingestión, en poco tiempo, de la alimentación prescrita; un mayor aumento de peso; alta hospitalaria precoz; mejoría en el estado de conciencia durante la alimentación; reducción del llanto e inducción al sueño, durante los procesos de dolor. Conclusión: A lo largo de la búsqueda no se encontró artículos de enfermería que aborden la actuación de esta practica terapéutica de estimulo a la succión no nutritiva, en neonatos y lactantes imposibilitados de ser amamantados, así como artículos que mencionen sus beneficios orofaciales. Los resultados se basaron en la reducida bibliografía relacionada con la temática.

Palabras-clave: estimulación, succión no nutritiva, neonatos, lactantes.

\section{Introdução}

A partir do ensino clínico em Unidades Neonatal e Pediátrica, foi possível manter contato com recém-nascidos e lactentes impossibilitados de amamentação, seja por limitaçóes próprias ou maternas. Ao atuar como acadêmica de enfermagem nestas unidades, foi percebido, talvez por desconhecimento, a não inserção da prática terapêutica, nestas crianças, do estímulo à sucção não-nutritiva. Foi constatado a não-inserção de tal atividade nas rotinas dos referidos setores.

A atividade terapêutica de estímulo à sucção não-nutritiva, que consiste simular o mamilo materno na boca desses bebês, pode ser feita através do dedo mínimo enluvado. Tal atividade contribui para o desenvolvimento da musculatura oral; maturação do reflexo de sucção; futura alimentaçáo oral em seio materno, transição para alimentação oral de forma rápida e fácil, facilidade de digestão, estimulação do trânsito intestinal e, associação, pelo recémnascido, da sucção à plenitude gástrica; ganho de peso; regulação dos estados de consciência do bebê; alta precoce [1-3].

Segundo a literatura, bebês prematuros com peso menor que $1800 \mathrm{~g}$ ou menores de 35 semanas gestacionais ao nascer, com dificuldade de sugar ou deglutir, ou apenas impossibilitados de sugar, passam a ser alimentados por sondas oro ou naso-gástricas. Portanto, devido a este impedimento, mesmo que momentâneo, destas crianças serem amamentadas diretamente ao seio materno, recomenda-se, ao alimentá-las, estimular o reflexo de sucção [1-3].
Porém, acredita-se que a atividade terapêutica de estímulo à sucção náo deva ser realizada exclusivamente em recém-nascidos prematuros. Visto que, esta prática, também torna-se válida em muitos neonatos e lactentes a termos, com deficiência no reflexo de sucção, em decorrência de doenças neurológicas, como acontece nos casos de hidrocefalia [1], ou ainda, em filhos de mães impedidas de amamentar, como ocorre em mulheres HIV positivas ou com câncer de mama.

Cabe lembrar que, de acordo com a literatura, no feto neurofisiologicamente normal, o reflexo de sucção surge a partir da $34^{\mathrm{a}}$ semana gestacional, o que proporciona, ao nascer, juntamente com os movimentos coordenados de deglutição e respiração, uma capacidade de serem amamentados diretamente ao seio materno [1]. Sabe-se ainda, que o sistema estomatognático, formado pelos arcos dentários, maxilas, mandíbula, osso hióide, ossos cranianos, músculos orais, espaços orgânicos, nervos e vasos sanguíneos, é responsável pelas funçóes de sucção, mastigação, deglutição, respiração, fonação e expressão facial [4]. Com isso, a amamentação além de proporcionar aporte nutritivo, imunológico e emocional, possibilita, através do próprio movimento de sucçáo, com que todas as funçóes deste sistema estomatognático se aperfeiçoem cada vez mais, contribuindo para o tônus muscular oral, desenvolvimento oro-temporomandibular e crescimento craniofacial adequados $[1,4]$.

Considerando, os benefícios da sucção nãonutritiva, bem como, os da amamentação fisiológica, o objeto deste estudo foi a atuaçáo dos enfermeiros, evidenciada a partir de literatura de enfermagem, em 
relação à prática terapêutica de estímulo à sucção nãonutritiva, em neonatos e lactentes impossibilitados de amamentação. As Questóes Norteadoras deste estudo são: Qual a atuação da enfermagem em relação à prática terapêutica de estímulo à sucção não-nutritiva, em neonatos e lactentes impossibilitados de amamentação? Quais os reais resultados esperados ou obtidos, evidenciados em publicações de enfermagem, relacionados a esta atividade terapêutica? Com isso, tais questionamentos serão respondidos através dos seguintes objetivos: descrever qual a atuaçáo da enfermagem a partir do estímulo terapêutico de sucção não-nutritiva, em neonatos e lactentes impossibilitados de amamentação e, identificar, em publicaçóes de enfermagem, os reais resultados esperados ou obtidos em relaçáo a esta atividade terapêutica.

Entendo que, a prática terapêutica de estímulo à sucção não-nutritiva, não deva ser prestada somente aos recém-nascidos prematuros com alimentação por sonda oro ou naso-gástrica, como indica a literatura [1-3]. Trata-se de um cuidado de enfermagem, devendo ser assegurado a todo neonato e lactente impossibilitado de amamentação direta ao seio materno, independentemente de sua maturidade pós-natal.

Portanto, esperamos contribuir através deste estudo, com a construçáo e aprofundamento do conhecimento científico na enfermagem, assim como, melhorar sua assistência em Unidades Neonatais e Pediátricas. Pois, de acordo com o Código de Ética dos Profissionais de Enfermagem [5], a mesma deve atuar na promoção, proteção, recuperação da saúde e reabilitação das pessoas, respeitando a vida, em todo seu ciclo vital e, assegurando, ao paciente, uma assistência livre de danos decorrentes de imperícia, negligência ou imprudência.

\section{Métodos}

Trata-se de um estudo bibliográfico com abordagem descritiva, tendo como fonte para o levantamento da produçáo cientifica, a Biblioteca Virtual em Saúde (BVS).

A Biblioteca Virtual em Saúde (BVS) é reproduzida de forma virtual, onde são distribuídas várias coleções de fontes de informação técnico-científica em saúde, podendo ser acessada através de uma metodologia comum, com o objetivo de facilitar o acesso à produção científica e divulgá-las [6].

A Biblioteca Regional de Medicina (BIREME) está vinculada à BVS e, é um centro dirigido pela Organização Pan-Americana de Saúde (OPAS), em convênio com o Ministério da Educação. Dentro do sistema BIREME, pode-se encontrar várias bases de dados virtuais, onde estão armazenados várias publicações referentes à área da saúde.

Nas diversas bases de dados virtuais são oferecidos formulários de pesquisa, que são ferramentas que, quando utilizadas de forma adequada, repercutirão diretamente na produção levantada. Estes formulários podem ser: o formulário livre, o formulário básico e o formulário avançado. Para ampliar a busca pelos artigos, foi utilizado, portanto, o formulário livre.

O levantamento das publicaçóes foi realizado de acordo com as palavras-chave non nutritive sucking, nonnutritive sucking, non nutritive sucking nursing, nonnutritive sucking nursing, non nutritive sucking stimulation, nonnutritive sucking stimulation, non nutritive sucking stimulation nursing, nonnutritive sucking stimulation nursing, sucção não nutritiva, estímulo da sucção não nutritiva, sucção não nutritiva enfermagem e estímulo da sucção não nutritiva enfermagem.

A maioria dos artigos encontrados na BVS disponibilizou apenas seus respectivos resumos, portanto, após seleção dos mesmos, foi necessário recorrer à outra fonte de dados chamada Ovid Technologies, a fim de acessá-los na íntegra. Porém, dos resumos escolhidos, poucos artigos foram localizados.

Foram encontrados 66 artigos com a palavrachave non nutritive sucking, porém, apenas 2 artigos eram publicaçóes de enfermagem que referiam-se ao tema e, puderam ser lidos na íntegra. Da mesma forma, foram localizados 40 artigos com a palavrachave nonnutritive sucking, mas, somente 2 artigos de enfermagem relacionados à temática, puderam ser analisados na íntegra.

Um dos artigos de enfermagem encontrados, na íntegra, pela palavra-chave nonnutritive sucking, também foi localizado com as palavras-chave nonnutritive sucking stimulation e nonnutritive sucking stimulation nursing.

Foi encontrado um único artigo, disponível na íntegra, pelas palavras-chave non nutritive sucking stimulation, sucção não nutritiva, sucção não nutritiva enfermagem, estímulo da sucção não nutritiva e estímulo da sucção não nutritiva enfermagem.

Foram encontrados 2 artigos de enfermagem com a palavra-chave nonnutritive sucking nursing, porém, apenas 1 artigo pôde ser lido na íntegra.

Artigos de enfermagem, relacionados à temática e, encontrados através das palavras-chave non 
nutritive sucking nursing e non nutritive sucking stimulation, não estavam disponibilizados na íntegra.

Após leitura criteriosa dos artigos científicos relacionados aos objetivos deste trabalho, foi realizada uma redação das 4 publicaçóes selecionadas.

\section{Resultados}

Quadro I - Caracterização das publicações de Enfer-

magem.

\begin{tabular}{|c|c|c|}
\hline Título & Origem & Abordagem \\
\hline $\begin{array}{l}\text { Sucção não nutritiva em } \\
\text { bebês prematuros: estudo } \\
\text { bibliográfico. } \\
\text { Conceição CL et al. [7]. }\end{array}$ & Brasileira & $\begin{array}{l}\text { Pesquisa } \\
\text { bibliográ- } \\
\text { fica }\end{array}$ \\
\hline $\begin{array}{l}\text { Meta analysis: Effects of } \\
\text { interventions on premature } \\
\text { infants feeding. } \\
\text { Daley HK et al. [8]. } \\
\text { (Meta- análise: efeitos das } \\
\text { intervenções na alimentação } \\
\text { de neonatos prematuros) }\end{array}$ & $\begin{array}{l}\text { Norte Ame- } \\
\text { ricana }\end{array}$ & $\begin{array}{l}\text { Pesquisa } \\
\text { bibliográ- } \\
\text { fica }\end{array}$ \\
\hline $\begin{array}{l}\text { The efficacy of developmen- } \\
\text { tally sensitive interventions } \\
\text { and sucrose for relieving } \\
\text { procedural pain in very low } \\
\text { birth weight neonates } \\
\text { Stevens B et al. [9]. } \\
\text { (A Eficácia do desenvol- } \\
\text { vimento das intervenções } \\
\text { sensíveis e sacarose para } \\
\text { aliviar processo de dor em } \\
\text { neonatos de muito baixo } \\
\text { peso ao nascimento) }\end{array}$ & $\begin{array}{l}\text { Norte } \\
\text { Americana }\end{array}$ & $\begin{array}{l}\text { Pesquisa de } \\
\text { campo }\end{array}$ \\
\hline $\begin{array}{l}\text { Effects of non-nutritive } \\
\text { sucking on nutritive sucking, } \\
\text { breathing, and behavior } \\
\text { during bottle feedings of } \\
\text { preterm infants } \\
\text { Pickler RH et al. [10] } \\
\text { (Efeitos da sucção não- } \\
\text { nutritiva na sucção nutri- } \\
\text { tiva, na respiração, e no } \\
\text { comportamento durante } \\
\text { a alimentação de infantes } \\
\text { prematuros) }\end{array}$ & $\begin{array}{l}\text { Norte Ame- } \\
\text { ricana }\end{array}$ & $\begin{array}{l}\text { Pesquisa de } \\
\text { campo }\end{array}$ \\
\hline
\end{tabular}

Discussão

A prática terapêutica de estímulo à sucção não nutritiva em neonatos ainda é um assunto muito recente, principalmente para os profissionais de enfermagem. Existem poucas evidências, em literatura de enfermagem, sobre a atuaçáo da mesma diante deste cuidado, bem como suas indicações e reais benefícios.

Os resultados encontrados são relacionados ao estímulo da sucção não-nutritiva somente em bebês prematuros, não havendo, portanto, pesquisas de enfermagem realizadas ou pelo menos disponíveis, na íntegra, com recém-nascidos e lactentes a termos, que estejam com o reflexo de sucção deficiente, ou apenas, impedidos de serem amamentados por questôes maternas.

Os benefícios da sucção não-nutritiva mencionados nos artigos de enfermagem foram: maior ganho de peso, alta precoce hospitalar, ingestão em menor tempo da alimentaçáo oral prescrita; melhora no estado de consciência durante a alimentaçáo em bebês com 2 minutos de estimulação antes da dieta; indução do sono, redução do choro e aumento do limiar álgico, em procedimentos dolorosos, sendo que a combinação da administração oral de sacarose com a sucção não-nutritiva mostrou maior eficiência na redução da dor; consumo de $94,4 \%$ da fórmula prescrita por bebês que receberam estimulação nãonutritiva antes da alimentação, enquanto bebês não estimulados apresentaram um consumo de 80,9\%.

Desta forma, observou-se que, a maioria das publicaçóes analisadas associou a atividade terapêutica, de estímulo à sucção não-nutritiva, à suas conseqüências no âmbito alimentar. Assim como, também foi possível observar que os resultados desta pesquisa, não mencionaram benefícios referentes ao desenvolvimento orofacial, tanto ósseo quanto muscular; ao estímulo do trânsito intestinal; à associação, pelo recém-nascido, da sucção à plenitude gástrica; à maturação do reflexo de sucção; à preparação para a futura alimentação em seio materno; à facilidade da digestão; à rápida e fácil transição para a alimentação oral.

Os resultados, quando comparados à literatura de apoio [1-4], mostraram-se inéditos, no que diz respeito ao maior consumo e ingestáo em menor tempo de alimentaçáo oral prescrita e, ainda, à indução de sono, redução de choro e aumento de limiar álgico, em procedimentos dolorosos.

\section{Conclusão}

Os resultados obtidos são baseados no reduzido acervo de enfermagem, encontrados e relacionados ao tema "sucção não-nutritiva em neonatos e lac- 
tentes impossibilitados de amamentação", tornando, com isso, evidente a necessidade de aprofundamento, diante deste assunto.

Apesar das poucas publicaçóes encontradas, acreditamos que este estudo possa contribuir para as reflexóes dos profissionais de enfermagem diante do cuidado abordado neste trabalho, a fim de melhorar a sua assistência, tendo por referência as necessidades de desenvolvimento e recuperaçáo da clientela em questáo. Pois, entendo que, a prática terapêutica de estímulo à sucção não-nutritiva em neonatos e lactentes impossibilitadas de amamentação, representa um cuidado de enfermagem que cumpre devidamente os Princípios Fundamentais e Responsabilidades, previstos no Código de Ética dos Profissionais de Enfermagem.

\section{Referências}

1. Figueiredo NMA. Ensinando a cuidar da mulher, do homem e do recém-nascido. 1a ed. São Caetano do Sul: Yendis; 2005.

2. Basseto MCA, Brock R, Wajnsztejn R. Neonatologia. Um convite à atuação fonoaudióloga. São Paulo: Lovise; 1998.
3. Brisque NFC, Rodrigues LC. Sucção em recémnascidos pré-termo e estimulação da sucção. Pró-Fono 2006;18(2):141-50.

4. Gomes CF, Trezza EMC, Murade ECM, Padovani CR. Avaliação eletromiográfica com eletrodos de captação de superfície dos músculos masseter, temporal e bucinador de lactentes em situaçáo de aleitamento natural e artificial. J. Pediatr (Rio J.) 2006;82(2):103-9.

5. Brasil. Conselho Federal de Enfermagem. Código de Ética dos Profissionais de Enfermagem. Resolução Cofen 311/2007.

6. Biblioteca Virtual Em Saúde - Bireme. Fundamentos. [citado 2007 Abril 10] Disponível em: URL:http:// www. bireme.br/bvs/bireme/P/fundamentos.htm.

7. Conceição CL, Fujinaga CI, Scochi CGS. Sucção não nutritiva em bebês prematuros: estudo bibliográfico. Rev Latinoam Enfermagem 2003;11(2):232-6.

8. Daley HK, Kennedy CM. Meta analysis: Effects of interventions on premature infants feeding. J Perinat Neonatal Nurs (San Francisco) 2000;14(3):62-77.

9. Stevens B, Johnston C, Frank L, Petryshen P, Jack A, Foster G. The efficacy of developmentally sensitive interventions and sucrose for relieving procedural pain in very low birth weight neonates. Nurs Res (New York) 1999; 48(1):35-43.

10. Pickler RH, Reyna BA. Effects of non-nutritive sucking on nutritive sucking, breathing, and behavior during bottle feedings of preterm infants. Adv Neonatal Care (Philadelphia) 2004;4(4):226-34. 